\title{
DETECÇÃO DE ANOMALIAS DE CONSUMO DE ÁGUA ATRAVÉS DE AUTOMAÇÃO PREDIAL
}

\section{Detection of water consumption anomalies through building automation BARBOSA, Lucas Sampaio'; LEITE, Brenda Chaves Coelho²}

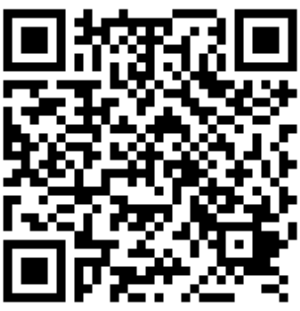

Palavras-chave:

Hidrômetro;

Gestão de Demanda;

Automação Predial;

Uso Eficiente da Água.

Keywords:

Hydrometer;

Demand Management;

Building Automation;

Eficient Water Usage.
RESUMO: Diante de perspectivas bastante pessimistas a respeito da disponibilidade dos recursos hídricos nas próximas décadas e da tecnologia disponível atualmente, deve-se lançar mão dessas tecnologias com vistas ao uso eficiente da água. A NBR 16782 (ABNT, 2019) propõe que os edifícios possuam um gestor de água, alguém, entre outras funções, seja responsável por acompanhar o consumo de água da edificação, identificar possíveis desvios neste consumo e conduzir a tomada de decisões para corrigir essas anomalias. Este artigo descreve uma lógica para o uso da automação predial como uma ferramenta no auxílio na detecção de anomalias no consumo de água. A partir da integração entre um sistema de automação predial já existente e os hidrômetros também já existentes, é proposta a implementação de lógicas de alarme que levam em consideração o histórico de consumo dos últimos cinco dias úteis para identificar desvios na demanda de água dentro de janelas de 15 minutos. Essa lógica pode ser útil para a tomada de decisões do gestor de águas sem necessariamente investir em novos equipamentos.

ABSTRACT: Faced with very pessimistic perspectives regarding the availability of water resources in the coming decades and the technology currently available, these technologies should be used with a view to the efficient use of water. NBR 16782 (ABNT, 2019) proposes that buildings have a water manager, someone, among other functions, who is responsible for monitoring the building's water consumption, identifying possible deviations in this consumption, and leading the decision-making process to correct these anomalies. This article describes a logic for using building automation as a tool to aid in the detection of anomalies in water consumption. From the integration between an existing building automation system and existing water meters, it is proposed to implement alarm logic that considers the consumption history of the last five working days to identify deviations in water demand within windows 15 minutes. This logic can be useful for water manager decision making without necessarily investing in new equipment.

\section{Contato dos autores:}

${ }^{1}$ BARBOSA, Lucas Sampaio: Tecnólogo em Automação, mestrando Profissional em Inovação na Construção na Escola Politécnica da Universidade de São Paulo. lucas.s.barbosa@usp.br.

2 LEITE, Brenda Chaves Coelho: Doutora em Engenharia Mecânica / Mestre em Arquitetura e Urbanismo Professora do Departamento de Engenharia da Construção Civil da Escola Politécnica da Universidade de São Paulo. bcleite@usp.br 


\section{INTRODUÇÃO}

Veriato (2015) traz previsões alarmantes no que concerne ao futuro da disponibilidade hídrica no mundo. A autora afirma que até 2050 a demanda por água irá aumentar cerca de $55 \%$ e o déficit de água será de $40 \%$, diante do aumento da demanda por alimentos.

Estes dados revelam uma divergência entre a aplicação e o conceito de desenvolvimento sustentável. "O desenvolvimento sustentável é aquele que atende às necessidades do presente sem comprometer a possibilidade das gerações futuras atenderem a suas próprias necessidades" (CMMAD, 1991, p. 46).

Para reverter o quadro apresentado por Veriato, são necessárias várias iniciativas para promover o uso eficiente da água. Segundo a NBR 16782 (ABNT, 2019, p. 3) o uso eficiente da água é a "utilização apenas da quantidade necessária e suficiente de água para a realização das atividades consumidoras, assegurando a saúde dos usuários e o desempenho do sistema". Isso significa que a partir do entendimento do funcionamento, componentes e processos envolvidos no sistema, bem como o tipo de usuário, sejam tomadas medidas que promovam esse uso eficiente na edificação através de procedimentos e tecnologias adequadas para tal.

A NBR 16782 (ABNT, 2019) contém conceitos e boas práticas relacionadas à conservação da água, a gestão da demanda, a gestão da oferta e do uso, operação e manutenção do sistema hidráulico. Dentro da seção de uso, operação e manutenção do sistema aparece a figura do gestor da água. Alguém que é responsável pelo monitoramento do consumo.

\subsection{A Gestão da Demanda e o Monitoramento do Consumo}

O conjunto de ações que "otimizam a operação do sistema hidráulico predial de modo a permitir a utilização da quantidade de água necessária para o desempenho das atividades consumidoras" (ABNT, 2019, p. 3) é conhecido como gestão da demanda. A principal ferramenta para essa gestão é o monitoramento de consumo (CBIC, 2017), realizado através da leitura de hidrômetros.

KALBUSCH (2006) avaliou como cinco dos principais sistemas de avaliação de sustentabilidade ambiental de edifícios de escritórios (BREEAM, GBTool, LEED, CSTB e CASBEE) tratam os sistemas prediais hidráulicos e sanitários e o uso da água. Entre os parâmetros avaliados de todos estes sistemas de avaliação está a existência de equipamentos de medição e monitoramento de água.

Segundo KALBUSCH (2006), deve haver uma revisão periódica dos indicadores de consumo para detectar possíveis anomalias de consumo. A CBIC (2017) prevê que esse acompanhamento seja feito, preferencialmente, diariamente. A ABNT (2019) orienta a definição de um gestor de água, responsável por esse monitoramento e que ao identificar elevações de consumo irá tomar as decisões necessárias para as possíveis correções do sistema hidráulico e a retomada dos indicadores de consumo.

Na Faculdade de Ciências da Administração de Pernambuco, implantou-se o gestor de águas em 2015. Neste ano houve uma redução anual no consumo de água de $430 \mathrm{~m}^{3}$ o que corresponde a uma redução de cerca $10 \%$. O monitoramento do consumo era feito através da leitura diária do hidrômetro e uma análise feita a partir do registro desses valores em planilhas (Soares, 2019).

Oyamada (2003) apresenta 3 formas de obter os dados de consumo: através das contas fornecidas pela concessionária; através de medições feitas in loco e através de tele medição. 
Essas formas podem ser combinadas entre si e ainda contar com uma setorização do consumo para ter uma melhor gestão da demanda.

Ao incluir a tele medição, os dados obtidos podem ser integrados a um sistema gestão predial (BMS). Estes sistemas são comumente utilizados em edifícios para monitorar e controlar os sistemas de aquecimento, ventilação e ar-condicionado além do monitoramento de energia do edifício. Ao integrar as leituras a esse sistema, também se torna possível a implementação de análises lógicas de alarme personalizadas que podem ajudar ao gestor de água na tomada de decisões.

\subsection{Objetivo}

O objetivo deste trabalho é descrever lógicas para detectar e alertar ao gestor de águas sobre possíveis anomalias no consumo, utilizando o Sistema de Gestão Predial (do Inglês, Building Management System), controladores e hidrômetros já existentes no edifício.

\subsection{Metodologia}

Oyamada (2003) elenca três parâmetros de controle importantes que podem ser obtidos a partir dos dados obtidos do sistema de tele medição de hidrômetros: Picos de vazão; vazões mínimas e vazões nulas. Devido à natureza dos instrumentos envolvidos no processo, não é possível determinar a vazão instantânea. Portanto, foi feita uma adaptação do conceito de Oyamada, de forma que o que será medido é a demanda nos últimos 15 minutos. Com base nesses três parâmetros foi desenvolvida uma lógica de controle que calcula:

- $\quad$ Período de Utilização;

- $\quad$ Período de pico de consumo dos últimos 5 dias úteis;

- $\quad$ Demanda máxima durante o período de pico;

- $\quad$ Demanda máxima média durante o período de pico dos últimos 5 dias úteis;

- Demanda mínima e máxima fora do horário de pico;

- $\quad$ Demanda mínima e máxima média fora do horário de pico nos últimos 5 dias úteis;

A partir desses parâmetros o BMS irá indicar os seguintes alarmes:

- $\quad$ Presença de demanda fora do período de utilização;

- Detecção de demanda máxima superior a $110 \%$ da média dos últimos 5 dias durante o período de pico;

- Detecção de demanda máxima superior a $110 \%$ da média dos últimos 5 dias fora do período de pico;

- Detecção de demanda mínima superior a $110 \%$ da média dos últimos 5 dias fora do período de pico.

Os programas previamente implantados no sistema já possuíam os históricos de consumo diário, mensal e anual, não sendo necessário o desenvolvimento desses parâmetros. 


\section{DESENVOLVIMENTO}

\subsection{Caracterização do Sistema}

O BMS em estudo, monitora e controla os sistemas de aquecimento, refrigeração e arcondicionado, de energia, além da integração com os hidrômetros em oito lajes comerciais de um edifício comercial em Belo Horizonte - MG. Cada pavimento típico possui duas prumadas de água potável e duas prumadas de água de reuso posicionadas em lados opostos do edifício. O fornecimento de água é de responsabilidade do condomínio, que repassa a fatura mensal aos condôminos.

Do ponto de vista do monitoramento do consumo, o sistema de automação conta com 2 controladores que se comunicam através de protocolo de comunicação BACNet. Cada controlador monitora 2 hidrômetros através de entradas digitais que detectam os pulsos elétricos enviados pelo hidrômetro de acordo com o consumo de água. Os controladores estão conectados a uma rede Arcnet utilizando cabeamento de par trançado RS-485, esta rede Arcnet possui um roteador BACNet que conecta seus controladores a uma rede BACNet/IP. Através desta rede é possível fazer conexão com um servidor web que permite a interface com o usuário. A figura 1 mostra um resumo da arquitetura dos controladores de um pavimento típico. Apenas estão representados na imagem os equipamentos envolvidos no monitoramento do consumo de água.

\section{Figura 1 - Arquitetura do Sistema}

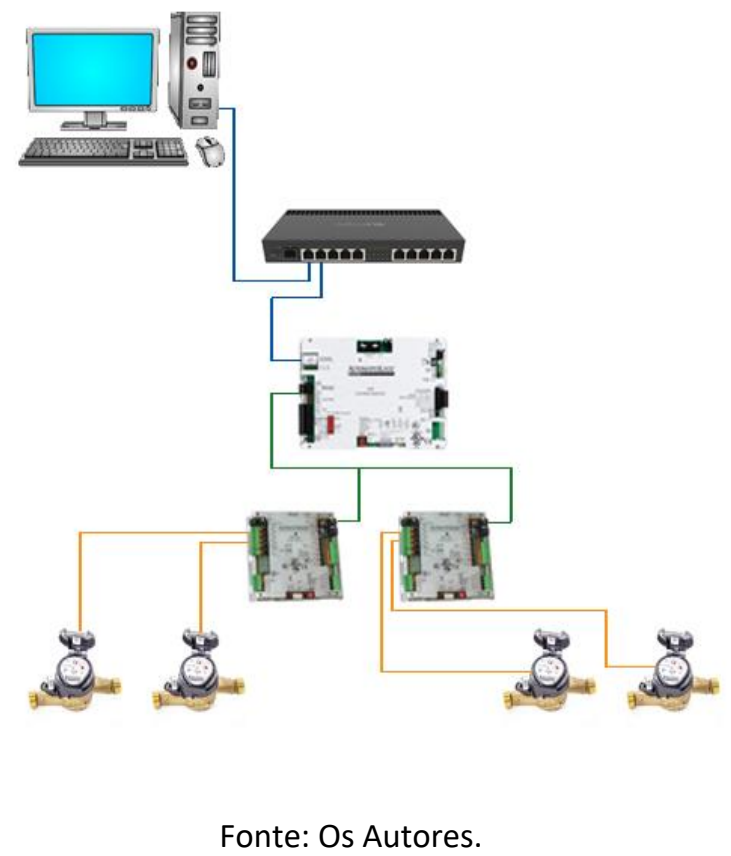

A leitura da demanda é feita através de uma entrada digital no controlador. O hidrômetro envia um pulso elétrico a cada litro de água que passa pelo instrumento. $O$ controlador contabiliza a quantidade de pulsos dentro de uma janela de tempo para então determinar o volume de água dentro daquela janela, sendo a demanda calculada a partir da razão entre o volume consumido e o tempo de janela de 15 minutos, neste caso.

\subsection{Período de Utilização}

$\mathrm{O}$ BMS possui controle de equipamentos de ar-condicionado. Esses equipamentos funcionam 
de acordo com uma programação horária que é determinada pelo usuário, que indica os dias e horários nos quais o pavimento está ocupado pelos seus usuários. Através de comunicação via protocolo BACNet, o controlador do hidrômetro se comunica com o controlador do arcondicionado e determina se o pavimento está ocupado ou não. Como o hidrômetro está instalado a jusante do registro que alimenta um lado do pavimento, quando fora do período de utilização, a existência de vazões mínimas é um sinal de vazamentos ou de consumo noturno (Oyamada, 2003).

\subsection{Período de pico de consumo dos últimos 5 dias úteis}

O BMS detecta o pico de demanda do sistema hidráulico e registro o horário em que este pico se deu. A cada dia o controlador registra esse horário em que se deu o pico e armazena em variáveis distintas para os últimos 5 dias úteis. $O$ controlador então calcula o horário médio dos últimos 5 dias e considera como período de pico o intervalo entre uma hora antes e uma hora depois deste horário médio de pico. A figura 2 representa o trecho do programa responsável por determinar o horário de pico. Esse período de pico só é utilizado na geração de alarmes após um período de 5 dias úteis consecutivos em que o controlador realizou registros válidos.

Figura 2 - Trecho do Programa Responsável pela Determinação do Período de Pico

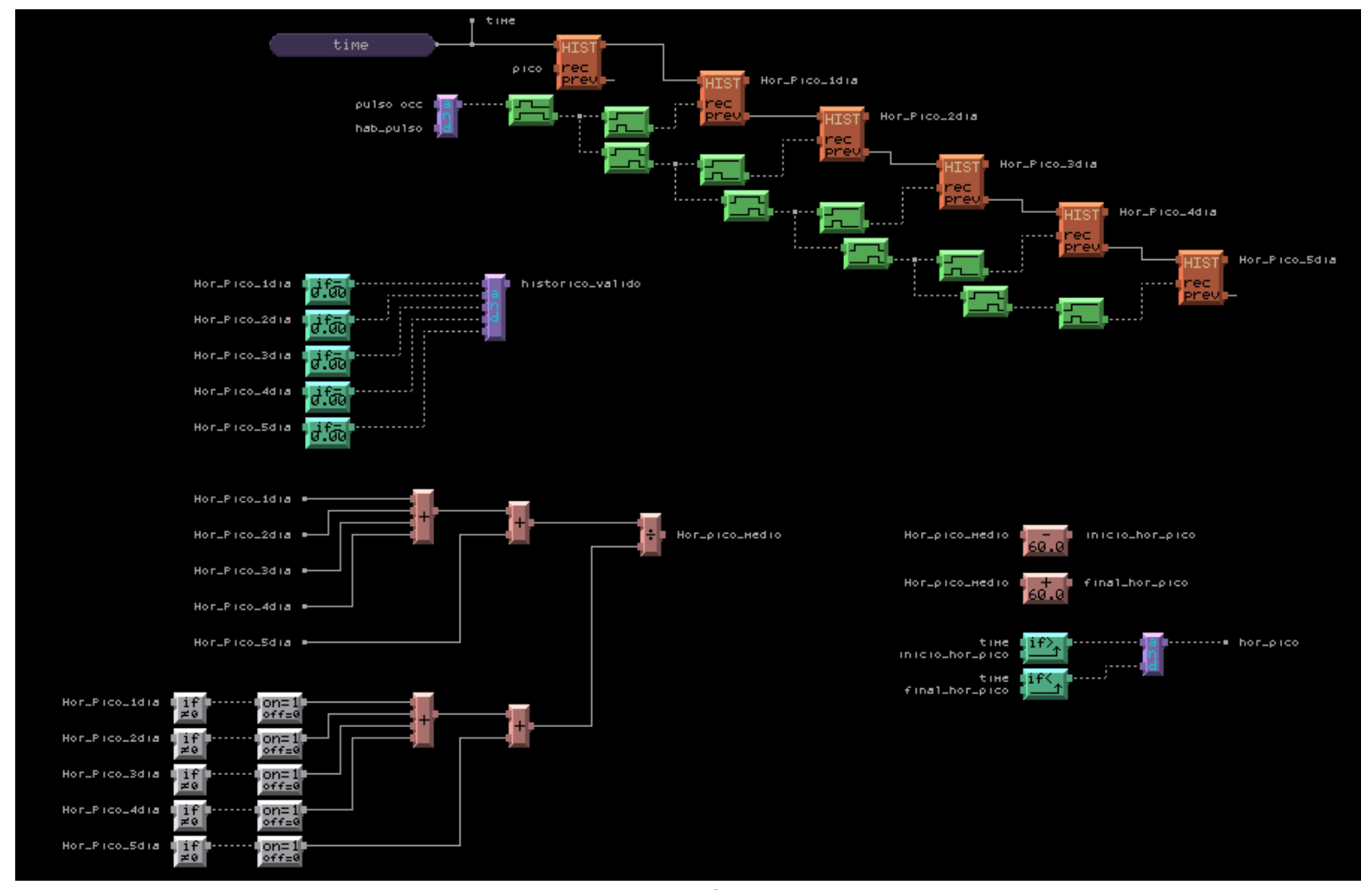

Fonte: Os Autores.

\subsection{Demanda máxima durante o período de pico}

O controlador identifica qual é a demanda máxima dentro do período de pico. Picos anômalos podem ocorrer devido a variação de pressão no fornecimento de água para o pavimento, devido ao mau funcionamento ou mau uso de algum equipamento hidrossanitário ou até mesmo devido a algum vazamento. 


\subsection{Parâmetros de demanda fora do período de pico}

De forma análoga às duas seções anteriores, o controlador determina quais sejam a demanda mínima fora do horário de pico, a demanda mínima média fora do horário de pico, a demanda máxima fora do horário de pico e a demanda máxima média fora do horário de pico.

Fora do horário de pico, a demanda máxima tende a ser menor; essa segregação de horários permite uma análise da demanda dentro de 3 períodos com perfis de consumo diferente e podem permitir uma melhor detecção de anomalias. Desconsiderando demandas que não sejam nulas, o aumento dessa demanda mínima também pode indicar vazamento.

Todos os parâmetros calculados pelo controlador ficam disponíveis em tempo real para o operador através de gráficos, sendo possível gerar relatórios em forma de planilha, enviá-los diariamente via e-mail, facilitando ainda mais o trabalho do gestor de água, assim como os alarmes gerados pelo sistema.

\section{CONSIDERAÇÕES FINAIS}

Através da utilização da automação predial é possível facilitar o trabalho do gestor de águas, fornecendo informação relevante na tomada de decisões para a correção de possíveis vazamentos, substituição de equipamentos hidrossanitários e até mesmo para campanhas de conscientização dos usuários.

Utilizando-se de algoritmos de controle, é possível determinar os intervalos de pico de demanda de água, as vazões máximas e mínimas e alertar ao gestor de água sobre possíveis anomalias no consumo.

A utilização do sistema existente facilita a implantação destas lógicas com o custo apenas da reprogramação e testes. Os instrumentos utilizados são utilizados para o monitoramento do consumo e não possuem precisão para determinar a vazão instantânea. As lógicas descritas, portanto, detectam as anomalias baseadas nas tendências de consumo, cabendo ao gestor de águas a análise se aquela variação anormal do consumo é de fato um evento que justifica uma intervenção ou se a variação é justificável por uma alteração no comportamento dos usuários.

\section{REFERÊNCIAS}

ASSOCIAÇÃO BRASILEIRA DE NORMAS TÉCNICAS. NBR 16782: Conservação de água em edificações Requisitos, procedimentos e diretrizes. Rio de Janeiro, 2019.

CÂMARA BRASILEIRA DA INDÚSTRIA DA CONSTRUÇÃO - CBIC (Brasília-DF). GESTÃO DE RECURSOS HÍDRICOS NA INDÚSTRIA DA CONSTRUÇÃO: CONSERVAÇÃO DE ÁGUA E GESTÃO DA DEMANDA. A Medição Setorizada como Instrumento de Gestão de Demanda de Água em Sistemas Prediais: Estudo de Caso: Programa Racional da Água da Universidade de São Paulo, Brasília-DF, 2017.

EM BUSCA do Desenvolvimento Sustentável. In: COMISSÃO MUNDIAL SOBRE MEIO AMBIENTE E DESENVOLVIMENTO (CMMAD). Nosso Futuro Comum. 2. ed. Rio de Janeiro, RJ: Fundação Getúlio Vargas, 1991. cap. 2, p. 46-71.

KALBUSCH, A. Critérios de Avaliação de Sustentabilidade Ambiental dos Sistemas Prediais Hidráulicos e Sanitários em Edifícios de Escritórios. São Paulo, 2006. 162p. Dissertação (Mestrado) Escola Politécnica, Universidade de São Paulo. 
SOARES, Anna Elis Paz et al. O MONITORAMENTO COMO FERRAMENTA DA REDUÇÃO DO CONSUMO DE ÁGUA POTÁVEL NA FACULDADE DE CIÊNCIAS DA ADMINISTRAÇÃO DE PERNAMBUCO - FCAP/UPE. Tecno-lógica, Santa Cruz do Sul, v. 43, n. 1, p. 42-48, 2019.

TAMAKI, Humberto Oyamada.A Medição Setorizada como Instrumento de Gestão de Demanda de Água em Sistemas Prediais: Estudo de Caso: Programa Racional da Água da Universidade de São Paulo. Orientador: Orestes Marracini Gonçalves. 2003. 151 p. Dissertação (Mestrado em Engenharia) - Escola Politécnica da Universidade de São Paulo. Departamento de Engenharia da Construção Civil, São Paulo, 2003.

VERIATO, Mara Karinne Lopes et al. Água: Escassez, crise e perspectivas para 2050. Revista Verde de Agroecologia e Desenvolvimento Sustentável, Pombal, v. 10, n. 5, p. 17-22, 22 dez. 2015. 